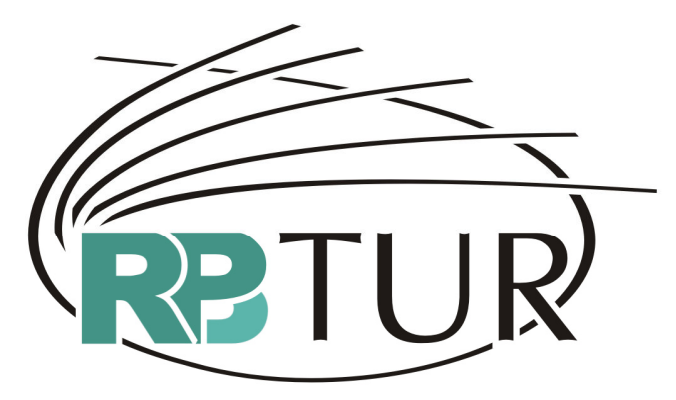

REVISTA BRASILEIRA DE PESQUISA EM TURISMO

\title{
O PROCESSO PARTICIPATIVO NO PLANEJAMENTO TURÍSTICO DO ESPAÇO RURAL DE ALFREDO WAGNER-SC
}

\author{
PARTICIPATORY PROCESS IN TOURISM PLANNING AT \\ ALFREDO WAGNER- SC RURAL SPACES
}

\section{EL PROCESO PARTICIPATIVO EN LA PLANIFICACIÓN TURÍSTICA DEL ESPECIO RURAL DE ALFREDO WAGNER-SC}

\author{
Carlos Loch $^{1}$ \\ Marinês da Conceição Walkowski
}

\begin{abstract}
Resumo: O presente artigo é resultado de uma Dissertação de Mestrado que teve como tema principal o planejamento participativo como instrumento do planejamento turístico do Município de Alfredo Wagner/SC. Este estudo se justifica ao identificar as modificações no espaço rural do Município, onde os agricultores têm enfrentando dificuldades na geração de renda e buscam dinamizar as atividades agrícolas e nãoagrícolas por meio do turismo. O objetivo deste artigo é analisar o processo participativo, visando mobilizar e sensibilizar os agricultores e agentes locais para o interesse turístico, sendo a participação um fator indispensável no planejamento turístico. Para tanto, a metodologia será uma pesquisa exploratória, a fim de descrever as características do Município e realizar um levantamento bibliográfico sobre o tema proposto. Como resultado desta pesquisa, foi observado, a falta de diálogo entre os principais órgãos públicos e a necessidade de buscar parcerias com a iniciativa privada. Contudo, foi possível mobilizar e sensibilizar os envolvidos por meio de uma análise da situação atual e futura, identificando as principais necessidades para o desenvolvimento turístico no Município.
\end{abstract}

Palavras-Chave: Processo participativo. Planejamento turístico. Planejamento municipal.

\footnotetext{
${ }^{1}$ Doutor em Engenharia Florestal pela Universidade Federal do Paraná e professor do Programa de Pós-Graduação em Arquitetura e Urbanismo da Universidade Federal de Santa Catarina. E-mail:loch@ecv.ufsc.br

${ }^{2}$ Bacharel em Turismo pela Faculdade Estácio de Sá de Santa Catarina (2005) e Mestre em Arquitetura e Urbanismo pela Universidade Federal de Santa Catarina (2008).

E-mail:marinesw@yahoo.com.br
} 
ABSTRACT: This paper is the outcome of a Master Theses focusing participatory processes as a tool for tourism planning in Alfredo Wagner (Santa Catarina State). The study was conducted to identify modifications in rural spaces in that place, where farmers are facing economic difficulties and have tried to enter tourism business to overcome them. The article analyzes participatory processes as starters to make rural producers and local agents get interested in tourism business, being participation the key factor for tourism planning. An exploratory research was conducted to describe the Municipality and also a bibliographic research. As e result it was observed that the main public agents do not dialog with each other and that partnership with private agents is needed. In spite of this lack of integration, involvement was achieved and it was possible to identify which are the necessary steps for tourism development.

Key-words: Participatory process. Tourism planning. Municipal planning tourism.

RESUMEN: Este artículo es el resultado de una Tesis de Maestría cuyo tema fue el proceso participativo como instrumento de la planificación turística en el municipio de Alfredo Wagner-SC. Este estudio se justificó por identificar las modificaciones del espacio rural en el Municipio de Alfredo Wagner-SC, donde los agricultores han enfrentado dificultades para obtener renta y tratan de dinamizar las actividades agrícolas y no agrícolas por medio del turismo. El objetivo de este artículo es analizar el proceso participativo, visando movilizar y sensibilizar a los agricultores y agentes locales para el interés turístico, siendo la participación un factor indispensable a la planificación turística. Fue realizada una investigación exploratoria para describir las características del Municipio así como una investigación bibliográfica sobre el tema propuesto. Como resultado, se observó la falta de diálogo entre los principales órganos públicos y la necesidad de buscar asociarse con la iniciativa privada. No obstante, se pudo movilizar y sensibilizar a los involucrados mediante un análisis de la situación actual y futura, identificándose las principales necesidades para el desarrollo turístico del municipio.

Palavras-Clave: Proceso participativo. Planificación turística. Planificación municipal.

\section{Introdução}

O planejamento do espaço rural surge a partir da necessidade de revalorizar os espaços naturais como fonte de riqueza, desempenhando um papel importante para o desenvolvimento local.

Os espaços rurais são compostos, entre outros, pelo patrimônio paisagístico que se diferenciam pela biodiversidade existente em cada território.

No espaço rural, a agricultura familiar vem enfrentando dificuldades na geração de renda. Entre as principais conseqüências estão a falta de emprego e o aumento da produtividade industrial, dificultando a participação dos 
pequenos agricultores familiares nos mercados competitivos. Assim, muitos habitantes abandonam estes municípios em busca de condições mais dignas de vida. O êxodo rural favorece o empobrecimento das famílias e ocasiona problemas sócio-culturais como o desordenamento urbano.

Neste sentido, surge a necessidade de dinamizar as atividades no campo na tentativa de resgatar a auto-estima do agricultor e revitalizar o espaço rural. As novas atividades não-agrícolas, também chamadas de agricultura pluriativa, são uma forma de incrementar a renda familiar.

Um exemplo de atividade não-agrícola é o turismo no espaço rural, que vem ganhando força à medida que possibilita ao agricultor, usufruir dos recursos como forma de atrair visitantes a sua propriedade e valorizar as atividades cotidianas.

Em relação ao município de Alfredo Wagner, situado a aproximadamente 110 km de Florianópolis, capital do Estado de Santa Catarina, a região se destaca por uma paisagem cênica exuberante, composta de atrativos naturais e culturais. Assim, foi realizado um projeto piloto com objetivo de sensibilizar os agricultores e os agentes locais, buscando despertar o interesse por atividades não-agrícolas como forma de melhorar a qualidade de vida dos habitantes locais.

Uma das estratégias utilizadas para a sensibilização e mobilização no Município foi a realização de um processo participativo, visando envolver os agricultores e agentes locais, identificar os possíveis atrativos, incentivar 0 turismo como forma de renda complementar e contribuir para o desenvolvimento sustentável.

\section{Universo conceitual}

\subsection{Planejamento do turismo}


O planejamento se faz necessário em qualquer área de atuação, pois estabelece estratégias viáveis para a criação de futuros empreendimentos, bem como auxilia no conjunto de decisões a serem tomadas.

O planejamento é um instrumento que busca ordenar as ações a serem tomadas, por meio de estratégias que visam alcançar o desenvolvimento sustentável de uma região. Com relação ao planejamento turístico, a sustentabilidade torna-se ainda mais importante no processo que visa promover o desenvolvimento de espaços rurais, atraindo uma melhor qualidade de vida aos moradores.

O planejamento do turismo é um processo racional cujo objetivo maior consiste em assegurar o crescimento e o desenvolvimento turístico. Este processo implica vincular os aspectos relacionados com a oferta, a demanda e, em suma, todos os sub-sistemas turísticos, em concordância com as orientações dos demais setores do país (MOLINA, 2005, p. 46).

Desta forma, o planejamento deve buscar integrar o turismo ao conjunto macroeconômico em que está inserido, por meio de metas, objetivos e estratégias.

Segundo Beni (2006), o planejamento envolve as seguintes etapas:

a) estudo preliminar (inventário): identifica e descreve a região objeto de estudo, inventário dos recursos existentes, descrição e identificação do estágio em se encontra o turismo na região;

b) diagnóstico: analisa os recursos ambientais e seu potencial de utilização na sustentabilidade do turismo, caracteriza a estrutura social, dimensiona a estrutura econômica e a infra-estrutura regional e caracteriza a oferta e demanda;

c) prognóstico: formula políticas e diretrizes de orientação e programas de ação para assegurar o planejamento estratégico, estabelece metas e projetos específicos, garantindo a integração da sustentabilidade do desenvolvimento econômico, turístico e social e adota programas que levem ao desenvolvimento sustentável do produto regional. 
Molina (2005) considera que planejar é prever o curso dos acontecimentos futuros, estabelecendo ações que conduzam à obtenção de uma situação desejada, mediante um esforço constante, organizado, sistemático e generalizado. Para tanto, estabelece as seguintes dimensões de acordo com a área de abrangência do planejamento:

a) planejamento nacional: é aquele que gera planos para serem executados em todo país;

b) planejamento regional: produz planos para um conjunto de estados ou províncias de um país, desde que estes reúnam características políticas, socioeconômicas, culturais e geográficas similares;

c) planejamento estadual ou provincial: é o que acontece no âmbito de um Estado ou província;

d) planejamento municipal: produz efeitos dentro dos limites de um município.

Cabe ressaltar que em relação ao planejamento municipal, considera-se que os efeitos podem sim, ir além do que é planejado para o município. Um exemplo seria a criação de um circuito turístico, atraindo demanda de outros municípios e para outros municípios próximos a ele.

Braga (2007) e Silva (2001) consideram que o planejamento turístico deve abranger não apenas um recurso (ou localidade), mas também seu entorno e apesar das possíveis dificuldades relacionadas à tomada de decisões, é importante considerar as regiões geograficamente homogêneas em vez de basear os estudos e as propostas em limites políticos e administrativos. Ainda, o ideal para o planejamento turístico é que os projetos estejam subordinados a programas e planos de ações, para que possíveis ações individuais contribuam para o desenvolvimento sustentável do turismo, contando com respaldo de ações públicas e da comunidade.

Já, para Barretto (2007), planejamento e turismo necessitam ser separados no ponto de vista conceitual, uma vez que o turismo inclui, de um lado, o planejamento e, do outro, a comercialização e, em determinado momento, ambos passam a interagir. Ainda, alerta que a maior parte das pessoas, inclusive as esferas governamentais, tem a visão de que o turismo se 
reduz a viagem, e o planejamento, à propaganda e à elaboração de pacotes. Esta visão tem contribuído com o planejamento desordenado que não atende aos interesses das comunidades receptoras nem aos pressupostos de conservação da natureza, mas apenas aos interesses econômicos dos grupos empresariais envolvidos.

O planejamento possui um caráter amplo e requer a utilização de estratégias que permitam desenvolver as potencialidades de um local, tornando-se um instrumento de desenvolvimento sustentável.

Para Ruschmann (1999) e Molina (2005), o maior problema da ausência do planejamento em localidades turísticas pode-se observar no seu crescimento descontrolado, que leva a descaracterização e a perda da originalidade das destinações. Além disso, motiva o empreendimento de ações isoladas, esporádicas, eleitoreiras e desvinculadas de uma visão ampla do fenômeno turístico. Também, há descontinuidade nas políticas de crescimento, alta rotação dos profissionais encarregados de conduzir o processo de planejamento e a informação estatística deficiente.

Esta realidade está presente em muitas localidades, onde um dos principais fatores que ocasionam as ações esporádicas são os diferentes interesses políticos e o não envolvimento da comunidade.

No processo de planejamento turístico, tal como o entendemos, a principal preocupação será a de combinar os recursos, criando condições indispensáveis para que seja satisfeita a procura turística potencial. Uma vez definido o papel do Estado em relação ao mercado turístico, este processo deverá contemplar também o contributo dos restantes parceiros sociais, onde se incluem os grandes agentes e organismos privados que estão presentes no mercado (MATIAS, 2007).

Para que o planejamento se torne um instrumento eficaz é preciso evidenciar desde a primeira etapa à participação efetiva dos interessados no desenvolvimento da atividade turística, no caso, poder público, iniciativa privada e comunidade. 


\subsection{0 processo participativo no planejamento turístico municipal}

O planejamento participativo tornou-se peça chave na validação de muitos projetos em diferentes áreas. Na atualidade, a participação tem sido muito questionada pela comunidade acadêmica e por órgãos governamentais com objetivo de inserir a comunidade nas discussões e debates em torno de questões fundamentais para a melhoria da qualidade de vida. Em relação ao turismo, a participação é ainda mais relevante, uma vez que os benefícios e os impactos desta atividade são refletidos pela comunidade receptora.

Segundo Molina (2005), o modelo de planejamento está sofrendo modificações, onde o planejamento centralizado está cedendo lugar a um outro mais participativo, que reconhece as capacidades e interesses locais e regionais.

O processo participativo está intimamente vinculado ao desenvolvimento e a sustentabilidade, uma vez que, desenvolvimento pressupõe mudança, uma transformação positiva, desejada ou desejável. Clamar por desenvolvimento (seja a partir de que ângulo for) só é concebível, portanto, no seio de uma cultura que busque a mudança ou que esteja conscientemente aberta a essa possibilidade como um valor social (SOUZA, 1996 apud PORTUGUEZ, 2002).

Nesta perspectiva, o planejamento do turismo deve estar fundamentado na participação popular, estimulando a consciência para que haja a verdadeira mudança. É preciso deixar as propostas saírem da esfera teórica e partir para a prática, envolvendo todos os atores responsáveis, priorizando ações que, em médio prazo, estejam dentro dos recursos possíveis.

O planejamento municipal visa incrementar e facilitar o desenvolvimento da atividade turística. A comunidade local deve fazer parte das decisões a serem tomadas como forma de garantir a integridade social.

Segundo Bissoli (2002, p. 51): 
O planejamento municipal, dentro da problemática geral de planejamento, consiste em um nível determinado de abordagem, que deve relacionar-se aos demais níveis de planejamento na medida em que o município não se coloca como realidade isolada, mas integra-se em uma região determinada, a qual, por sua vez, assume características próprias.

De acordo com os autores, devem-se levar em conta as características de cada Município, a fim de que se possam destacar suas principais qualidades e torná-las um atrativo a ser desenvolvido pelo turismo de forma organizada.

Para tanto, é preciso que haja uma interação, conforme quadro abaixo:

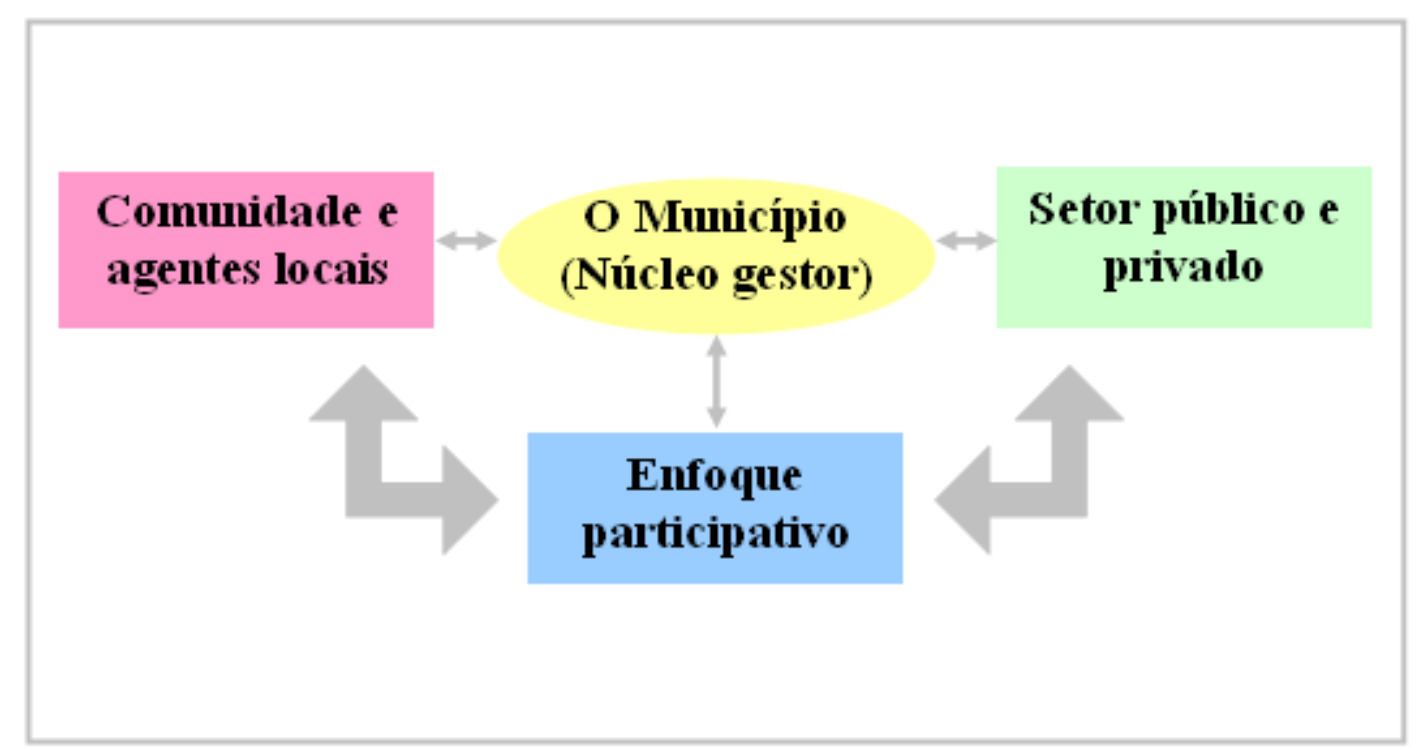

Quadro 1: Planejamento municipal e enfoque participativo.

Fonte: Autora.

Esta relação entre os principais componentes de uma sociedade contribui para que o conhecimento seja expresso de forma clara e haja maior grau de legitimidade e aceitação das ações por parte da comunidade.

O processo participativo deve ser ajustado a cada organização. Isto implica em que não existem "métodos participativos" prontos. É necessário ajustar o ritmo às características sociais, culturais, técnicas, entre outras, do grupo em questão, ou seja, a flexibilidade e a criatividade são parte integrante de um Enfoque Participativo (CORDIOLI, 2001). 
É preciso destacar que existem diversas metodologias e técnicas de planejamento participativo, mas nenhuma poderá ser aplicada sem ser adaptada de acordo com a realidade de cada município.

Neste sentido, a participação efetiva dos envolvidos tende a ser positiva, pois envolve não só a comunidade, mas também, os aspectos mais relevantes de sua cultura.

Ainda, o desenvolvimento sustentável poderá ser decorrência de um processo participativo que assegure o crescimento de ações conjuntas. Neste sentido, busca-se compreender o surgimento do termo e sua relação com a atividade turística.

\section{Caracterização do Município de Alfredo Wagner/SC}

O município de Alfredo Wagner/SC destaca-se pela diversidade de atrativos espalhados por várias localidades do Município. Sua denominação surgiu em homenagem ao cidadão Alfredo Henrique Wagner, falecido a 20 de outubro de 1952, grande responsável pelo progresso e desenvolvimento da região (WAGNER, 2002).

Alfredo Wagner/SC, está localizado no Planalto Serrano, faz parte da $13^{a}$ Regional, em uma pequena região da Serra do Tabuleiro, delimitando-se com os municípios de Bom Retiro, Rancho Queimado, Leoberto Leal, Ituporanga, Angelina, Anitápolis e Imbúia.

Segundo o Censo realizado pelo IBGE (2000), o município de Alfredo Wagner foi fundado em 29 de Dezembro de 1961, é dotado de clima temperado seco e temperatura média anual é de $19^{\circ} \mathrm{C}$. A colonização é alemã e italiana com população aproximada de 8.376 habitantes, 3.629 homens e 3.405 mulheres. As religiões predominantes são: católica, evangélica e luterana. 
Com relação à colonização de origem alemã e italiana, o Município se destaca pelas construções antigas com fachadas em estilo germânico, igrejas, monumentos, decorações, artefatos antigos e manifestações culturais, como o artesanato em madeira.

O Município possui aproximadamente $40 \%$ da população vivendo na zona rural, cuja base econômica é a agricultura. Assim, aproximadamente $80 \%$ do total arrecadado resulta do cultivo da cebola, fumo, milho, a agropecuária e a produção de leite.

As 1.668 propriedades rurais, somam 50.994 hectares, destas, 88,91\% apresentam área inferior a 50 hectares e $46 \%$ das propriedades com menos de 10 hectares. São 1.450 propriedades vivendo da produção de cebola como sua principal fonte de renda (IBGE, 2000).

Em relação a capital catarinense (Florianópolis), o Município está distante aproximadamente $110 \mathrm{~km}$ e faz parte do Planalto do Alto Vale do Itajaí. As vias de acessos são a BR 282 e SC 302.

O município, com extensão de $732 \mathrm{~km}^{2}$, divide-se em três principais regiões: a Catuíra, antiga Colônia Militar Santa Teresa; o Centro, que consiste toda região do estreito, Picadas e Barracão, antes considerados distrito de Bom Retiro; e a localidade de Lomba-Alta.

Acrescenta-se a essa caracterização a beleza cênica da região, despertando o interesse por um estudo mais complexo da potencialidade do Município. Para tanto, foi proposto uma oficina de planejamento participativo, visando identificar parte do potencial existente e as deficiências para o desenvolvimento da atividade turística.

\section{Oficina de planejamento participativo}


A reunião para realização da oficina ${ }^{3}$ ocorreu no dia 27 de Outubro de 2007, na Câmara de Vereadores do Município de Alfredo Wagner. Inicialmente foi apresentada a pergunta principal que, após aprovada pelos participantes, serviu de base para as demais etapas. Assim, prosseguiu-se com as demais perguntas que conduziram os participantes a alcançar o objetivo da oficina.

O objetivo desta oficina foi identificar os principais pontos a serem trabalhados que iriam auxiliar posteriormente na elaboração de um plano de ações, metas e estratégias. Para obter uma visão macro do Município, buscouse envolver os agricultores e agentes locais. Os demais objetivos da oficina foram:

a) estruturar o planejamento turístico no Município;

b) analisar a situação atual;

c) analisar a situação futura;

d) definir linhas e estratégias de ação previstas para 2007 e 2008 (Cronograma).

A autora da pesquisa assumiu a postura de moderadora, definiu os grupos de trabalho e aplicou o método participativo.

\subsection{A estrutura da oficina}

A oficina foi dividida em dois momentos. Primeiramente foi realizada uma análise da situação atual, em três etapas. Em seguida, partiu-se para análise da situação futura, em seis etapas. Em todas as etapas buscou-se utilizar a problematização. As etapas da oficina foram:

\section{a) Análise da situação atual}

\footnotetext{
3 Para elaborar esta etapa, a autora da pesquisa, participou de uma capacitação sobre Planejamento Estratégico Participativo, nos dias 07 a 11 de Maio de 2007, ministrada pelo Moderador Sérgio Cordioli, obtendo conhecimento necessário para realizar a oficina nesta pesquisa.
} 
O que temos?

Nesta primeira parte da oficina, realizou-se um balanço do contexto atual dos atrativos no Município, em especial, seus avanços e deficiências. Concluiu-se esta etapa com a análise do envolvimento institucional - papéis e pessoas de contato.

Como está?

Nesta etapa foram analisados os pontos fracos e fortes dos atrativos apontados anteriormente.

\section{O que queremos?}

Buscou-se uma definição clara dos envolvidos de quais as ações e etapas para desenvolver a atividade turística no Município.

\section{b) Análise da situação futura}

Como chegar lá?

Buscou-se apontar as principais estratégias.

Quais recursos necessários?

O objetivo foi identificar quais seriam os recursos necessários a serem buscados em termos de parcerias, materiais e financeiros.

Quais os recursos potenciais?

Esta etapa teve por objetivo definir quais os recursos já existentes e disponíveis no Município que poderiam ser utilizados.

Quem serão os responsáveis? 
Eleger um núcleo provisório de pessoas que auxiliariam na organização de atividades no Município.

Até quando?

Estipular meta prevista para o ano de 2007 e 2008.

Atividades previstas.

Propor ações a curto prazo, até o final de 2007 (outubro, novembro e dezembro).

Avaliação da oficina.

Propor uma avaliação geral do evento, visando certificar se os objetivos foram claros e satisfatórios aos participantes.
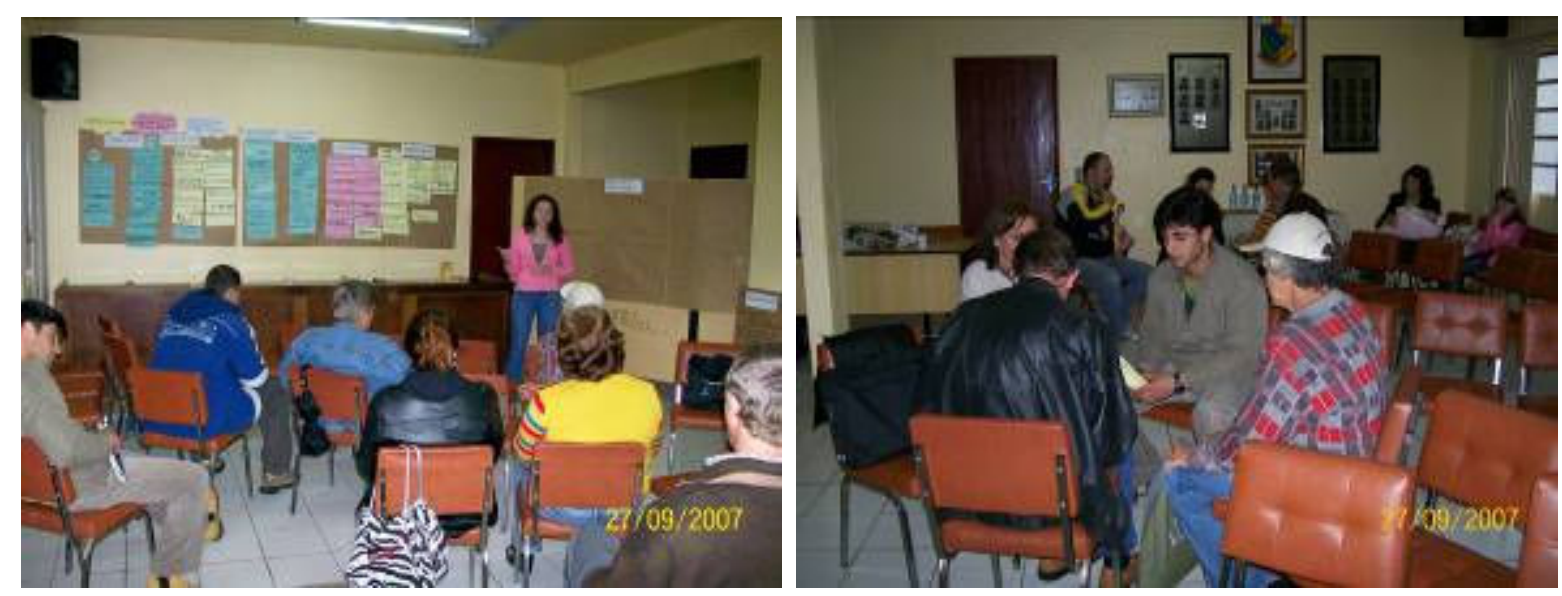

Figuras 1 e 2: Oficina de planejamento participativo e trabalho em equipe. Fonte: Autora

\subsection{Resultados da oficina}

Esta etapa teve por objetivo levar os participantes a realizar um levantamento dos pontos fortes e fracos em termos de turismo no Município. Os resultados foram obtidos por meio de respostas nas tarjetas e trabalhos em grupo. 


\section{a) Análise da situação atual}

\section{O que temos?}

- Povo receptivo.

- Mata virgem.

- Recursos naturais.

- Localização estratégica.

- Próximo dos grandes centros.

- Hospitalidade.

- Montanhas e cachoeiras.

- Propriedades com trilha, cachoeiras, cavernas (vestígios de moradia indígena) e vários animais.

- Orientação técnica (da autora e Acolhida na Colônia).

- Agricultura familiar.

- Aspecto cultural.

- Agroecologia.

- Grande quantidade de água e recursos hídricos.

Durante esta etapa, os grupos foram divididos de forma aleatória, onde se pretendeu unir pessoas de diferentes funções e assim, garantir os interesses individuais de cada participante. A análise da situação futura refletiu todos os aspectos mais relevantes no Município. Estes aspectos, na visão dos participantes, são um diferencial e potencial para o turismo. Entre os pontos mais relevantes, citado pela maioria, está a localização do Município, já que é um local de passagem pelos visitantes, visto como estratégico, pela proximidade com os grandes centros. Assim, será necessário trabalhar o potencial dos aspectos naturais e culturais, buscando mapeá-los e localizá-los para que os visitantes possam se motivar a conhecer os atrativos.

\section{Como está?}


Pontos fortes:

- Está despertando para o turismo.

- Fácil acesso a mecanismos de desenvolvimento (créditos).

- Está sendo mais divulgado.

- Diminuição gradativa dos impactos ambientais.

Pontos fracos:

- Falta mostrar mais as nascentes.

- Falta conscientização ambiental.

- Falta capacitação.

- Falta um projeto piloto.

- Falta consciência e há poucas ações em relação à educação ambiental.

- Falta acesso a trilhas e estradas.

- Pouco apoio dos órgãos públicos.

- Falta incentivo e recursos.

- Maior atuação da Secretaria Municipal de Turismo.

Neste item, cada participante, levando em consideração os dados apontados pela questão anterior e a situação macro do Município, buscou-se analisar o estado atual dos atrativos existentes, considerando os pontos fortes e fracos. Observa-se que em sua maioria, há mais pontos negativos para serem trabalhados. Um exemplo são as questões voltadas para o meio ambiente, onde à participação dos técnicos do micro-bacias, permitiram visualizar a falta de conscientização ambiental e a falta de capacitação nesta área. Outro fator relevante é o não envolvimento da Secretaria Municipal de Turismo nesta oficina, por falta de interesse do mesmo.

\section{0 que queremos?}


- Ação/prática.

- Parcerias com a iniciativa privada.

- Capacitação técnica dos agricultores.

- Mapeamento dos potenciais.

- Interatividade com os visitantes.

- Crescimento cultural.

- Melhorar a renda nas propriedades.

- Evitar o êxodo rural.

- Turismo simples.

- Poder praticar nossas idéias.

- Desenvolvimento sustentável.

- Conhecer exemplos bem sucedidos.

- Valorizar o que temos.

Nesta pergunta, foi possível ter uma visão geral das necessidades individuais e de cada ator em sua comunidade, pois cada participante exerce um papel fundamental no Município e acaba conhecendo realidades distintas. Dentre os itens levantados, está a necessidade de um mapeamento dos potenciais já que, o Município carece de informações mais atuais. Nesta pesquisa foi realizado um levantamento dos atrativos potenciais, utilizando-se de GPS (Global Positioning System) e máquina digital.

Os demais itens, serão conseqüências dos trabalhos que poderão ser realizados em Alfredo Wagner.

\section{b) Análise da situação futura}

Como chegar lá?

- Rede de parcerias (Banco do Brasil, Acolhida, Prefeitura, Iniciativa privada, MDA, MTUR, Sebrae, Petrobrás).

- Definir os eixos/atores. 
- Mais créditos.

- Falta só acontecer.

- Muita perseverança.

- Motivação dos envolvidos.

- Utilizar as estruturas existentes (EPAGRI ${ }^{4}$, MB2, Secretaria, outros).

- Treinamento dos envolvidos (manipulação de alimentos, paisagismo).

- Diagnóstico participativo nas propriedades.

- Legislação sobre atendimento ao turista.

Com base nas experiências de cada participante, foi possível traçar as estratégias consideradas adequadas para desenvolver a atividade turística. Um exemplo são as parcerias públicas e privadas, para buscar recursos para obras nas propriedades rurais. Com relação à utilização da estrutura existente, observa-se a falta de diálogo entre os órgãos públicos e a própria comunidade para que ambos possam trabalhar em conjunto. Outro aspecto importante é a falta de legislação sobre atendimento ao turista (turismo rural) que têm dificultado a comercialização de produtos de origem rural aos visitantes, além da falta de normas para a implantação de empreendimentos turísticos no espaço rural.

Quais são os recursos necessários?

- Assistência técnica mais especifica.

- Sinalização e divulgação no site.

- Mais recursos financeiros.

- Guia de turismo.

- Infra-estrutura viária.

- Infra-estrutura da propriedade.

- Levantamento das necessidades da propriedade.

\footnotetext{
${ }^{4}$ Empresa de Pesquisa Agropecuária e Extensão Rural de Santa Catarina
} 
Neste item cada participante levou em consideração quais os recursos serão necessários captar, com base nos dados apontados anteriormente, ou seja, parcerias com a iniciativa pública para infra-estrutura viária e/ou com a iniciativa privada para assistência técnica. Durante a problematização, ficou evidente a falta de profissionais aptos a elaborar projetos para captar recursos. No município, alguns projetos são elaborados pelo corpo técnico do MicroBacias, porém para projetos turísticos não há profissionais capacitados nesta área.

Quais são os recursos potenciais?

- Mão-de-obra.

- Recursos humanos sem capacitação.

- Técnicos em saneamento (Micro-bacias).

- Propriedades interessadas.

- Parcerias para cursos (SENAR ${ }^{5}$ e EPAGRI).

- Plano de desenvolvimento da propriedade.

- União entre os interessados.

Neste item, foram apontados os recursos (materiais e técnicos) que estão disponíveis ou que poderiam ser mais bem utilizados. Um dos exemplos são os cursos oferecidos pelos profissionais da EPAGRI em parceria com o Microbacias. Estes profissionais já atuam a mais tempo no Município, mas possuem dificuldade para envolver toda a comunidade.

Quem serão os responsáveis?

Buscou-se ao longo da oficina, reconhecer quem são as lideranças que exercem influência sobre os demais. De forma democrática, cada participante

\footnotetext{
${ }^{5}$ Serviço Nacional de Aprendizagem Rural - SENAR
} 
pode eleger um núcleo que poderá encaminhar e fiscalizar ações a curto prazo no Município.

Até quando?

Foi eleito um prazo para que as ações fossem feitas entre o ano de 2007 a 2008. Este prazo está de acordo com as ações previstas pela Associação Acolhida na Colônia e visam preparar o Município para formar um circuito turístico, para tanto, algumas atividades já estão sendo realizadas.

Atividades previstas

Visitas técnicas em outros Municípios como Urubici e Rancho Queimado e realização de diagnóstico participativo nas propriedades.

Avaliação da oficina

A avaliação foi realizada individualmente pelos participantes e no geral, foi considerada positiva. Dentre os pontos levantados foram:

- A importância da participação de todos.

- Definir um local com mais segurança.

- O trabalho em grupo.

- A produtividade do grupo.

- A expectativa do grupo.

- Sugestões para que o intervalo ocorra no meio dos trabalhos.

- O enfoque participativo e democrático.

- Questões bem elaboradas, no entanto, com maior tempo para reflexão.

Os pontos levantados pelos participantes demonstram um amadurecimento e consciência das reais necessidades do Município. Para esta 
pesquisa, busca-se um aproveitamento dos dados levantados a fim de criar propostas e estratégias que visam suprimir estas necessidades.

\section{Conclusões}

O Município de Alfredo Wagner, nesta pesquisa, foi alvo de uma iniciativa para se desenvolver a atividade turística, por meio de uma metodologia participativa. Nesta etapa houve o envolvimento de membros da comunidade e dos representantes dos principais órgãos estaduais públicos como a EPAGRI e Prefeitura Municipal.

Com relação ao espaço rural de Alfredo Wagner, durante as visitas de campo observou-se o grande potencial turístico a ser desenvolvido nas propriedades, bem como o interesse dos agricultores em trocar experiências com os visitantes. Contudo, apesar do potencial identificado por meio da observação, não há um planejamento que busque antes de qualquer outra iniciativa, organizar os trabalhos em grupo para que todas as partes interessadas alcancem 0 desenvolvimento do turismo no Município. As iniciativas realizadas nos últimos anos, constituíram trabalhos isolados, que não tiveram continuidade por parte das instituições de ensino e por parte também da Secretaria Estadual de Turismo.

Os participantes presentes na oficina de planejamento participativo são representantes de diferentes classes e demonstram a importância de se trabalhar a multidisciplinaridade de funções para que as idéias não favoreçam apenas uma classe. Neste sentido, buscou inteirar o grupo para que ambos pudessem contribuir para o desenvolvimento turístico de acordo com suas habilidades.

Os resultados obtidos com a oficina refletem a visão macro que os participantes tiveram sobre a realidade do município de Alfredo Wagner. 
Dentre os resultados mais relevantes, ficou clara a falta de diálogo entre os principais órgãos públicos. Um exemplo são os inúmeros cursos disponíveis pelo Micro-bacias, mas que não chegam a todas as comunidades, sendo necessário buscar interação com outros órgãos, como por exemplo o SENAR, para as capacitações.

Sobre os aspectos levantados pela oficina, observou-se que apesar de reconhecerem o potencial e o diferencial em termos de recursos naturais e culturais do Município, nada tem sido feito para aproveitar estes recursos.

Os envolvidos reconhecem a necessidade de buscar parcerias com a iniciativa privada, mas carecem de profissionais capacitados para elaborar projetos e captar estes recursos. Ficou evidente a falta de um profissional para coordenar ações que visem minimizar as carências.

Por fim, a oficina possibilitou um maior envolvimento dos agricultores no processo de planejamento turístico no Município, uma vez que os mesmos se dispuseram a fazer parte desta pesquisa e se interessaram por desenvolver o turismo em suas propriedades. Partindo desta constatação, foram propostas novas ações como: a) um diagnóstico participativo em cada propriedade, objetivando identificar o potencial turístico de cada uma e os pontos a serem melhorados, b) um plano de ações, objetivando melhorar a infra-estrutura das propriedades, a sinalização turística, a qualidade dos serviços oferecidos, a assistência técnica nas propriedades e a melhoria na qualidade de vida dos agricultores locais.

\section{Referências}

BRAGA, D. C. Planejamento turístico: teoria e prática. Rio de Janeiro: ELSEVIER, 2007.

BARRETTO, M. Cultura e turismo: discussões contemporâneas. Campinas, SP: Papirus, 2007.

BENI, M. C. Análise estrutural do turismo. 11 ed. São Paulo: SENAC, 2006. 
BISSOLI, A. Planejamento turístico municipal com suporte em sistemas de informação. 3 ed. São Paulo: Futura, 2002.

CORDIOLI, S. Enfoque participativo um processo de mudança: conceitos, instrumentos e aplicação prática. Porto Alegre: GENESIS, 2001.

INSTITUTO BRASILEIRO DE GEOGRAFIA E ESTATÍSTICO (CENSO IBGE, 2000). Município de Alfredo Wagner. Disponível em: <http: \|www.ibge.gov.br>. Acesso em: 24 de Junho de 2005.

MATIAS, À. Economia do turismo: teoria e prática. Lisboa: Instituto PIAGET, 2007.

MOLINA, S. Turismo: metodologia e planejamento. Bauru, SP: EDUSC, 2005.

PORTUGUEZ, A. P. Agroturismo e desenvolvimento regional. São Paulo: HUCITEC, 2002.

RUSCHMANN, D.V.M. Turismo e planejamento sustentável: a proteção do meio ambiente. 5. ed. Campinas, SP: Papirus, 1999.

SILVA, J. G. da. Velhos e novos mitos do rural brasileiro, 2001. Disponível em: <www.rcl.fao.org>. Acesso em: 18 de Abril de 2007.

WAGNER, A. Alfredo Wagner. Florianópolis: Pallott, 2002. 